\title{
Investigating the Literary Competence Development of the Tertiary Level's EFL Learners: The Novel as a Model
}

\author{
Ahmed Khalis Shalan \\ Department of English, College of Languages, Nawroz University, Duhok, Kurdistan \\ Region - F.R. Iraq
}

\section{ABSTRACT}

This research paper is dedicated to investigate the development of the 'literary competence of the EFL learners at 3 universities within Duhok Governorate area during the academic-year 2014-2015.

Justifying the need for this study in an introduction, stating the problem; specifying the scope of the aims of the study, confining the study to certain limits, drawing certain hypotheses which the study could argue about, making survey of some related literature in the field, giving definition to the key terms of the study, finally the researcher designed a questionnaire in order to use it as a tool in investigating the development of the EFL learners' assumed 'literary competence'.

EFL Learners at 4 departments of English in 3 universities within the area of Duhok Governorate were involved as a studycommunity.

Next, after selecting the research-sample, distributing the questionnaire forms, collecting back the forms with feedback, analyzing the collected data, the researcher finally got important findings about the reality and the development of the EFL learners' 'literary competence' at the tertiary level, and among them are the following:

1- EFL tertiary level students have got a very poor literary competence,

2- EFL tertiary level students' literary competence should have been acquired during the pre-college learning levels through reading of the mother-tongue's literature, and then could be developed through reading the EFL literature,

3- EFL tertiary level's students could hardly improve their literary competence standard during the EFL 4-year-college English literature reading, and

4- Others.

The findings not only paved the way to draw important conclusions about the development of the tertiary level EFL learners' 'literary competence' in novel study, but also provided the possibility to generalize the arrived at conclusions to include the teaching of poetry, short story, and drama; and consequently, the conclusions led to put forward necessary recommendations on how to improve the 'literary competence', and the 'aesthetic taste and mood' of the EFL learners in general.

KEYWORDS: Literary awareness, literary competence, literary knowledge.

\section{INTRODUCTION}

"The work in the foreign language, if it is to be truly literary work, must be regarded as an extension of capacities already developed, at least partially, in mother-tongue literary work, but these capacities will be refined through contact with literature from a foreign culture."

(Brumfit \& Carter 2000: 189)

Reading or studying literature as part of an EFL or ESL curriculum has since long been a matter of concern. On the part of the learners it relates to reflective merits such as the learning, or cultural, or aesthetic ones, while

Academic Journal of Nawroz University

(AJNU) Volume 6, No 3(2017), 12 pages

Received 1 February 2017; Accepted 1 April 2017

Regular research paper: Published 24 August 2017

Corresponding author's e-mail: akhshalan@gmail.com

Copyright (C2017 Ahmed Khalis Shalan

This is an open access article distributed under the Creative

Commons Attribution License. part of the pedagogues it relates to the communicative objectives set for the said curriculum.

In order to negotiate the meaning of any literary text read by the EFL learner, who are supposed to have developed a minimum level of what we might, if it were, call it a "literary competence" during the long period (almost not less than 9 years) of exposure to ELL before they join the tertiary level. Hence, scholars, in particular Culler (cited in Lazar 2013, p. 12), argued that, by analogy with Chomsky's 'grammatical competence', effective readers of literary texts are seen as to possess an assumed 'literary competence' or 'literary awareness' (henceforth LitAw) as Sonia Zyngier called it (Watson \& Zyngier, 2007: p. 194). But logically, any assumed 'literary competence', or LitAw is not a notion which comes flying; it rather comes crawling like a baby during a long time of literaturereading. So, it needs time to mature into a fine tangible and sufficient proficiency in literature. But, a matured literary competence could not be easily gained. This is, in fact, because of the difficulties that may face the literature

Original article | doi: 10.25007/ajnu.v6n3a82 
teaching-learning process, which the learner is going through. Duff \& Maley (2003) made an attempt to diagnose the following difficulties of teaching literature to the tertiary level EFL learners:

Linguistic difficulty: This may involve syntactic complexity, lexical density, or discoursal organization,

Text length difficulty: Longer texts appear may to some learners more difficult, while for others shorter ones may present more difficulties,

Cultural difficulties: The 'outsider' can hardly share fully the range of references of an 'insider'.

References range difficulty: for instance works such as Eliot's 'The Waste Land' which cannot be fully appreciated without attached notes, and

- Conceptual difficulty: Here, William Blake's poetry provides good examples of deceptively 'simple' writing, whereas it so deep to understand easily.

(Duff \& Maley 2003 p. 7)

However, while teaching an introduction to English literature, the writer of this paper frequently heard the EFL learners either grumbling or crouching about literature as a subject taught in the tertiary level and its educationally-realistic usefulness, because the majority of those learners, as Short and Candline described them, are:

"... non-native school-leavers who are rarely equipped for the demands made upon them by the literary departments of universities and colleges. They come with impoverished command of language, in many cases, and little exposure to the reading of complex, connected text, whether literary or nonliterary." (Candline, ed. 2000: p. 92)

Culturally speaking, as there is an opinion rests on the assumption that any early 'literary taste' starts developing first through the contact between the individual and his native-language literature, the above-mentioned Cndline's argument, in fact, stimulated and prompted the writer of this research-paper, as a pedagogue, to investigate the freshman-learners' (total of 120) opinions about:

- Firstly, the whys and wherefores that made them join a department of English, and

- Secondly, how far they are proficient in respect of their contact with their native-language literature.

As an initial step, a simply-designed open-ended inquiry form was made (figure No.1):

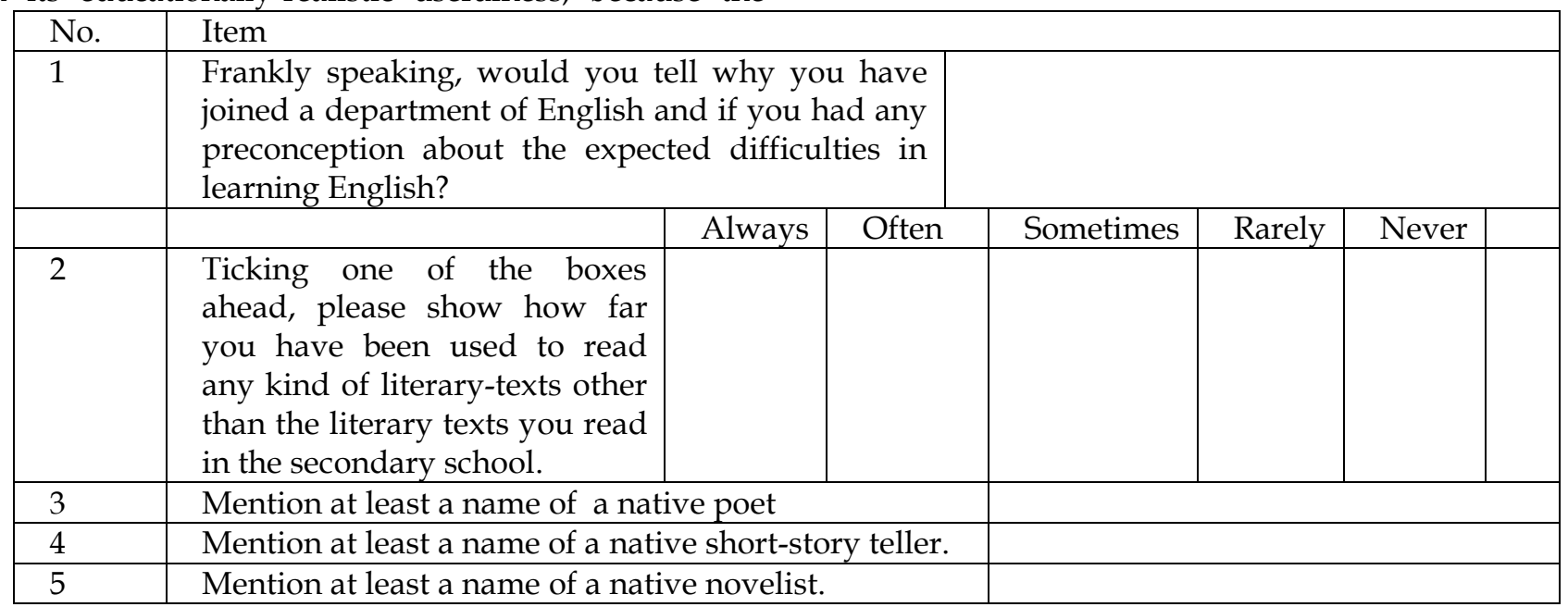

Fig 1: Open-ended inquiry

Surprisingly, the results of the inquiry have shown very significant indicatives of the learners' attitudes toward learning English and reading literature, which can be summarized as follows:

\section{1- Variance one:}

$65 \%$ of the learners willingly wished to join the Department of English; almost instrumentally motivated to learn English, as a tool for achieving further purposes, and equipped, to a certain extent, with preconceptions about the somewhat expected difficulties of English language learning, but with very little concern over matters related to literature, as Brumfit \& Carter describe them:

...who have some understanding of literature as a phenomenon in their own culture, but with inevitably limited language, originally learnt with a more instrumental intention. (Brumfit \& Carter 2000: p.30)

This, in other words, means that such students are concerned more in learning EFL to use it as a tool for a purpose other than enjoying its literature and culture.

$16 \%$ of the learner willingly wished to join the Department of English only just for appearances' sake; with lesser preconceptions, if none at all, about the difficulties of learning EFL and the related issues, because they are stimulated by motives based on, if it were, 'gaining a so-called prestige of being in a foreignlanguage-class', and

- $19 \%$ joined the Department of English unwillingly, because they missed the chance to join another branch of study; either because of the regulations of admission to university, or any other reason, and eventually they find themselves studying English language against their will, i.e. to get an academic degree whatever that is.

2- Variance 2:

The results of this showed the following: 
Table 1: Variance 2

\begin{tabular}{|l|l|l|l|l|l|l|}
\hline & $\begin{array}{l}\text { Total Stud. } \\
\text { No. }\end{array}$ & Always & Often & Sometimes & Rarely & Never \\
\hline Frequency & 120 & & & 9 & 9 & 102 \\
\hline Percentage & 120 & & & $7.5 \%$ & $7.5 \%$ & $85 \%$ \\
\hline
\end{tabular}

3- Variances 3,4 and 5:

Table 2: Variances 3,4 and 5

\begin{tabular}{|l|l|l|l|l|}
\hline Variance & Total Stud. No. & No. & Percentage & Name \\
\hline 1 & 120 & 15 & $12.5 \%$ & Ahmedi Khani, \\
\hline 2 & 120 & 0 & $0 \%$ & Nil \\
\hline 3 & 120 & 0 & $0 \%$ & Nil \\
\hline
\end{tabular}

Paradoxically, when the researcher asked the Using the study of the novel as a model, the study aims respondents on Variance 1 about how happened and they knew Ahmedi Khani and if they ever read any verses of Khani, the well-known Kurdish philosopher and poet, most of them replied that they knew him by his statue which is raised-up in the heart of Dukok City, not by his verses

Finally, and significantly, such information obtained from the afore-mentioned inquiry would definitely be a good prompt to put the learners' literary competence and their readiness to accept reading literature as part of their English language-study on the table of discussion. Furthermore, in addition to the difficulties diagnosed by Duff \& Maley, it can also be assumed, by close regular observation that:

"... it is not possible to appreciate the world of literature unless the everyday cultural background (the raw material which literature has used) has already become familiar at an earlier level of learning."

(Littlewood, in Brumfit \& Carter, 2000:

p.180).

Hence, the researcher argues that the assumed 'literary competence' of learners of the type above-inquired should be in question.

Depending on the results of the said inquiry as a rationale, and taking the novel as a model, this paper is dedicated to identify the growth of any assumed 'literary competence' of the EFL learners during the 4-yearcollege-study of the novel at 3 universities in Duhok Governorate area.

\section{1- Problem of the Study}

As a matter of fact, neither all people like to read literature, nor all the EFL learners incline to read or study literature as a part of the fulfillment of their study-duty. Furthermore, not only few numbers of EFL learners' community even complain and express doubts about the educationally-justified usefulness of reading any type of literature as part of an EFL curriculum. Similarly, unknowing that it is inevitable to learn any language apart of its literature and culture, some EFL learners might be heard, here and there, complaining: 'I came here to learn English Language not to read English Literature!'

Hence, it was generally presumed that most of the EFL learners, joining a department of English, either demonstrate a modest standard of 'literary competence', if not lacking such a quality at all.

2- Aims of the Study: at identifying:

1- The standard of the tertiary level EFL learners' 'literary competence' at the universities in the area of Duhok Governorate.

2- any significant differences in the literary competence standard among Duhok Governorate universities' EFL learners.

2- Identifying any significant differences in the 'literary competence' standard among the EFL learners according to university, college, and gender.

3- Value of the Study:

The study value lies in its findings, as they would be of a great help to the teachers of literature and provide them with significant benchmarks about the growth of an assumed 'literary competence' of their students, especially in respect of how to improve the standard of the literary-competence, or in finding creative approaches to teaching literature. It would also provide assistance to research-workers, especially to those who have concerns about such rarely-discussed topics of the literary-competence standard of the EFL learners at the universities of Iraq, and universities in Kurdistan region in particular.

Limits of the Study:

The study is limited to elicit the 'literary competence' standard of the 4-year-college EFL learners in different departments of English at universities located in Duhok Governorate/ Iraqi-Kurdistan during the academic-year 2014-2015.

\section{4- Hypotheses:}

It is hypothesized that:

1- The EFL learners, joining a college to study English language have very poor standard of an assumed 'literary competence',

2- No significant differences can be found concerning the 'literary competence' standard between the EFL learners at 3 universities in Duhok Governorate area.

3- No significant differences can be found in the 'literary competence' standard among the EFL learners at 4 colleges of 3 universities in Duhok Governorate area.

4- $\quad$ The EFL learners at a tertiary level can develop and improve their 'literary competence' throughout the 4year-college-study,

5- The EFL male-learners can develop better standard of 'literary competence' compared to EFL female-learners.

Original article | doi: 10.25007/ajnu.v6n3a82 
6- In Duhok Governorate area universities, the tertiary level EFL learners at any state-university can develop better standard of 'literary competence' compared to their peers in the private-sector-universities.

\section{7- $\quad$ Definition of Basic terms}

1- Literary awareness: It is the mental quality which depends on the activities which promote student's sensitivity of the verbal aesthetic experience. (Zyngier- in Watson \& Zyngier, 2007: p.195)

2- Literary education: It is the process of enhancement, whereby the noticing process allows additional information to enter the students' cognitive system and have the potential to develop their interpretive abilities (Hanaure- in Watson \& Zyngier, 2007: p.170)

4- LitAw: The student's best ability to read and understand literary works and enjoy its aesthetic appeals. In terms of Psychology, Piclett, (in Brumfit \& Carter, 2000: p.278) call it 'literariness, and defined it as "mental objects communally possessed and linked together by some common essence . . . are of the same ontological status as the matter studied in the physical sciences"

\section{8- Related Literature:}

As a matter of fact, to know what stimulates the student to read a work of literature is an extremely sophisticated and complicated matter, because many factors with details have to do with such a sophisticated concern. Teachers of literature often meet EFL learners with very little knowledge about the meant learners' tendency to understand and enjoy the literature they read in the language classroom.

Hence, paying very little attention, by the EFL teachers, to such an important matter of the students' attitudes towards what they read in the lesson of literature, the lesson of literature has in the recent decades become one of the core topics of the EFLT research-work community. Consequently, a very considerable work of research, related to the topic of the EFL learners' literary and aesthetic mode and literary education has been going on. Being in a literary mode has technically become to be known either as 'literary competence' (Prumfit \& Carter 2000), or 'literary awareness' (Zyngier, Fialho, and Parado Rios- in Watson \& Zyngier, 2007: p. 194) or 'LitAw' (Hanauer- in Watson \& Zyngier, 2007: p.196). Therefore, 'literary competence' has been taken to be "the student's best ability to read and understand literary works and enjoy their aesthetic appeals" (see section 7 above).

In their Literature and Language Teaching, Brumfit \& Carter (2000 p.15) laid some parameters of how the 'literary competence' can be defined. They argued that literature provides language resources to be exploited to the full, and the learner is given an active interactional role in making sense of such language resources (Brumfit \& Carter 2000 p.15). Thus, the opportunity is given to the learners to make sense of a text which provides the status that helps them to develop their 'literary competence'. But, Brumfit \& Carter also argued that although students' learning goes through an integrated language, the literary study should form a core part of any suggested literature teaching course. But, this is not and cannot be the whole story of teaching literature, whether on the part of the pedagogue or on the part of the learners when developing an assumed 'literary competence' (ibid p.16). This is, because a value judgment of this may be affected by socio-historical factors which reflect a particular ideology, as well as difficulties may face all teachers of language and literature, in particular the teachers working in a situation of teaching literature in an EFL surroundings (ibid p.16). Among the said difficulties, they furthermore, emphasize two important points. The first is that in the context of EFLT 'different cultures' would value 'different things' for students from other cultures. The second point is that teachers need to make provision for sensitizing learners, or to develop their 'literary competence'.

Hence, Brumfit \& Carter believe that EFL literature teachers should create effective strategies of reading to their students, but providing that such strategies should "form a component of a culture specific set of norms and expectations which often need to be explicitly taught while developing the 'literary competence" (ibid p.18). And, in order to give both, the EFL learners and teachers, an additional opportunity to develop a 'literary competence, they even quoted from (Kachru 1983 a) the debate about what is called 'contact literatures' which "exhibit stylistic and discoursal characteristics which differ markedly from the traditional canon of English literature and bring with them related culture-specific problems of interpretations" (ibid p.19). They, furthermore, argued that: "It is unreasonable to expect that non-native speakers to approach literary texts in English with the intuitions of a native speaker" (ibid p.20).

Finally, in order to promising a situation for the development of any 'literary competence', they recognized that teachers of literature in EFLT surroundings need to contextualize the linguistically and literarily integrated syllabus by: a- Following linguistic and non-linguistic norms in text selection, b-Using languagebased methods, and c-Realizing that some aspects of language organization may create problems more crucial than others, especially in the case of EFL learners (ibid p.20).

On the other hand, in their important article, Revisiting Literary Awareness, Zyngier, Fiallho, and Prado Rios (in Watson \& Zyngier, 2007) put a question which needs a crucial answer:

- Why Literary awareness?

In order to give a reasonable answer, they argued that most of the EFL learners acquire a rather transient knowledge about literature, because they, for their tests, rely on a pool of dates and facts about novels and authors, which are forgotten as soon as the examinee leave the examination whole, and the result would be almost nothing in respect of building any kind of LitAw. So, they quoted from (Rosenblatt 1938) that any LitAw can be developed from the need to promote critical and autonomous readers who could both experience the text 
and substantiate their statements from the linguistic perspective (Zyngier et al- in Watson \& Zyngier 2007). And thus, the LitAw can be developed from a 'casual one to a causal one and from random and intuitive to the systematic (Frye 1957, 1990: p.7-cited in Zyngier et al. p. 194).

However, (Zyngier et al: 2007) put another question which also needs a crucial answer:

- Is there such a thing as mastery of literary reading or should we consider a variety of competences? Then, adding another question:

- Are first language readers more competent than foreign language readers (Zyngier 1999- cited in Watson \& Zyngier 2007)?

But, answering the latter question they said that being a first language speaker does not mean being a competent reader of literature (Zyngier et al- in Watson \& Zygnier, 2007 p. 195). Hence, they hold a study which indicates that LitAw owes much to developments in language awareness (Sinclair 1985 p.7- cited in Zyngier et al, 2007 p.195). Furthermore, quoting from Carter (1993: p. 142), they argued that the process of LitAw development hold that the process involves: a- Properties of language i.e. its creativity and playfulness and its double meanings; bEmbedding language within culture; c- Forms of the language we use; and $\mathrm{d}$ - Close relationship between language and ideology (Zyngier et al. 2007: p.195).

Making a step further, they argued that LitAw involves five elements:

1- Exposure: This occurs with direct contact of a reader with a text. The more the learners read the more practice they obtain. But, exposure depends on four factors:

- Setting: This refers to the situation in which the act of reading is taking place,

- Duration: This accounts for time-length of exposure,

- Intensity: This refers to the depths of reading, including skimming scanning, extensive reading and intensive reading (quoted from Grellet 1984; 1990: p.4; Grwer \& Pearson 1986, Hoey 1991), and

- Type: This indicates the manner the students respond to how reading is done (silently, individually, in a group, etc)

196) (Zyngier et al, 2007: p.

2- Cross-linking: This includes:

- Projection which answers for the reader's anticipation (quoted from Wilding, 1982 p. 271; Sinclair 1991 a)

- Inference which helps the reader to arrive at a general picture from clues in a text.

- Intentionality: which assumes that the readers are able to construct meaning, based on what they think the author intended

(Zyngier et al, 2007:

3- Reference Build-up: This indicates a fact that the more connections the readers can make the more complex their understanding of a text. And this depends on integration and sequentiality which varies according to:

-difference in background: the readers' repertoires are always unique, as people differ in the experience they undergo and absorb,

- the integration and sequentiality: This can be expressed by the learner need to build literary repertoire which is progressive and sequential and justified in the reader's response to new texts.

4- Adjustment: Here, depending on their repertoire, the learners can reject, accept, or revise the information they gain from the text, which eventually means that the process involves matching what is expected of the text to a body of knowledge and assimilating the new.

5- Productivity: This refers to a strong component of LitAw that encourages personal expression and the use of imagination, which suggests participation in verbal art to help the students choose, describe, identify, and discuss stylistic patterns (ibid pp. 196-7-8).

Among the discussions of such a cognitive issue of the learners' mode and tendency to read literature, an important additional participation came from Hanauer (in Watson \& Zyngier 2007). Hanauer suggested an Empirical approach to the literature education process based on facts collected orderly from classroom (or home) activities. And this approach value, in Hanauer's (2007: pp. 169-170) exact words, "... it provides information from the world of practice and response." and "... derives from an interdisciplinary, empirical method."

In 1999, Hanauer developed a model of literary education, which came as a combination of understanding from adjoining fields of cognitive psychology, applied linguistics, and literary education (quoted from Hanauer 1999- cited in Hanauer 2007: p. 170). This, in fact, was an attempt to define the core role for the system of attention in developing literary knowledge by making use of preliminary thoughts developed in relation to 'LitAw' made by Zyngier 1994 a, 1994 b- in Watson \& Zyngier 2007).

Hanauer's (1999) model of literary knowledge growth was based on three basic principles:

1- Literary knowledge development: This development is presented in terms of the student's interpretive ability, which marks an increasing ability to positively deal with literary texts, and eventually to enhance learner's ability to choose, concentrate on, and make use of information found in a literary text in order to achieve a contextually relevant interpretation (Hanauer 1999- in Watson \& Zyngier, 2007: p. 171).

2- Cognitive concepts of enhanced ability: This is related to two particular processes:

-Analysis, and

- Control (quoted from Bialstok 1999, 1994).

Analysis refers to a change happens gradually in the type of information stored in long-term memory, whereas control involves a move in the ability to concentrate intentionally on specific information. In this sense, it 
implies the process of using attention in certain representations of knowledge and the talent to move from one presentation to another (Hanauer- in Watson \& Zyngier, 2007: p. 171).

3- Understanding the system of attention: This system, as explained within the cognitive paradigms, controls the quality and quantity of data coming to the learners' minds by choosing the type of information to deal with from the range that an individual is exposed to. For attention Hanauer quoted from Tomlin and Villa (1994), arguing that attention is divided into three interrelated functions: a- Alertness: It is a 'general readiness to deal with incoming stimuli',

b- Orientation: The directing and attentional resources to a certain kind of stimuli, and

c- Detection: Defined as 'the cognitive registration of sensory stimuli' (Hanauer- in Watson \& Zyngier, 2007: p. 171).

Here below, in (Figure 2) one can see that Hanauer model basically shows a circular movement which focuses on the function of systematic instruction of plain information in increasing the amount of information that is seen by the literary student, which in its turn enhances the learner's awareness of specific types of information found in a literary text.

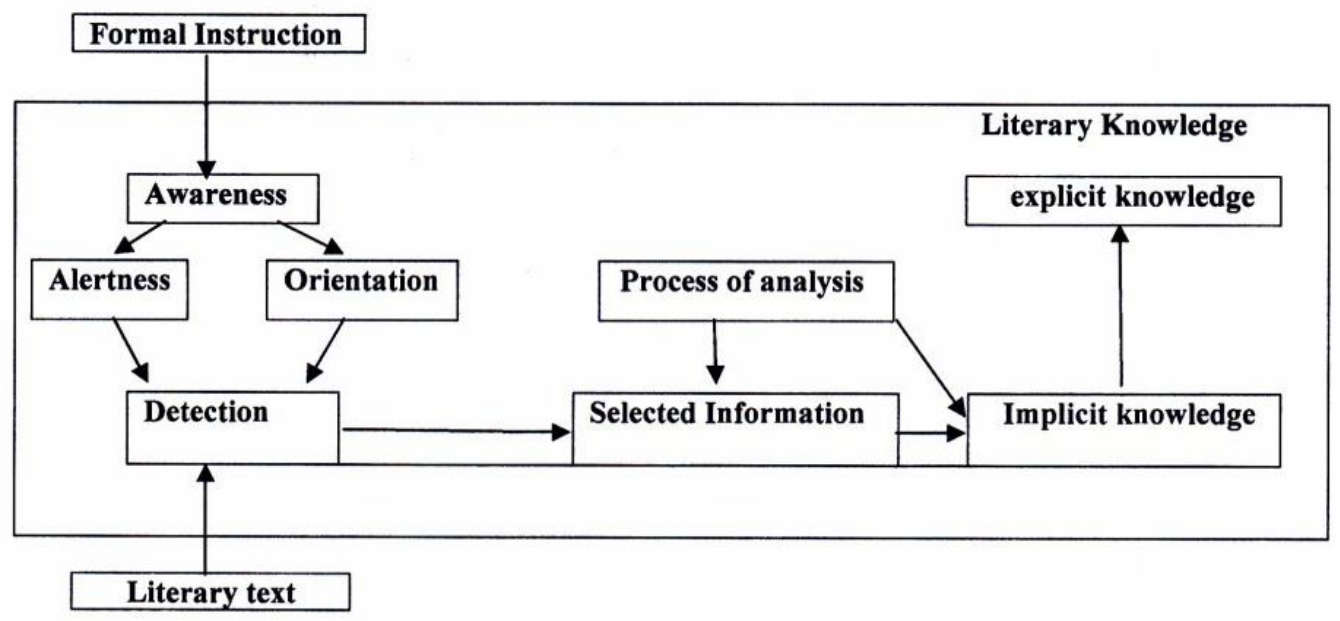

Figure 2: Adopted from Hanauer's model of literary knowledge development (2007)

In brief, Hanauer's model suggests that awareness and the system of attention have major functions in the literary knowledge development, i.e. the starting point is an awareness of information within the literary text (Hanauer 2007: p. 173).

Finally, in terms of EFLT/L, as the reading of literary works is basically a sort of communication between the learners and the writers of different types of literature, and this, originally, is a kind of communicative language ability. It is worth mentioning that the communicative language ability is supposed to be a combination of adjacent components (Hedge 2003: p.46), (linguistic competence, pragmatic competence, discourse competence, strategic competence, and fluency in the three skills of language speaking, writing, and reading), and for sure not to forget Chomsky's grammatical competence'. Hence, the use of the term 'literary competence' (in parallel with the afore-said competences) would sound, for the aims of this study, more appropriate than the other two terms, 'literary education' and 'LitAw'.

\section{9- Methodology}

\section{9-1 Questionnaire Design:}

In order to identify the students' assumed literarycompetence standard and development, a questionnaire form (see appendix II) was designed to include twenty statement-items (for better understanding from the learners, the statement-items were given in three versions: English, Kurdish, and Arabic). Ten of the saiditems included positive attitudes towards studying and reading English novels, and the other ten items included negative attitudes towards reading or studying English novels and stories. The questionnaire's version was presented to a panel of juries specialized (see their names in appendix I) in methods of teaching EFL to examine its adequacy and convenience. Examined so, the questionnaire statement-items were given the following scales: 1- always; 2- often; 3- sometimes; 4- rarely; 5never, with marks distributed as follows:

* The positive-attitude-statement-items were given successive scores from 5 to 0 )

* Overturning the scores distribution, the negative-attitude-statement-items scores (from 0 to 5 ).

\section{9-2 Study Population: Sample and Participants:} 9-2-1 Population

Students of departments of English at 3 universities in Duhok Governorate area were chosen as a population of the study.

9-2-2 Study-sample Participants Selection:

The research-sample participants were selected from among the population above-mentioned in (9-2-1) according to a systematic approach. Depending on the student-name lists, and as the average number of the students names in the lists was around 30-35, the student of every fifth name in the list was selected as a participant in the research-sample. Thus, six participants 
from each stage of study were chosen to collect 24 participants from each department of English, and thus, a total number of 96 participants were gathered (from 4 departments/ 4 colleges/ 3 universities) to be the community of the study.

\section{9-2-3 Administration of the Questionnaire}

Distributing the 96 questionnaire forms and getting them back from the research-sample participants, responses collected from the questionnaire forms were classified in tables according to the following codes:

Universities: Uni. Nawroz (NzU; Uni. Zakho (UoZ); Uni. Duhok UoD

Colleges: College of Languages (CoL); College of Arts (CoA); College of Basic Education (CoBE)

Departments: Department of English (DoE)
Stages: freshmen (1); sophomores (2); juniors (3); seniors (4)

Genders: Male (1) Female (2)

9- 2- 4 Data Analysis and Discussion

Examining the provability of the hypotheses set in section (6) of this study, the data collected from the questionnaire feed-back indicated the following:

Firstly: For the first hypothesis which states that "The EFL learners, joining a college to study English language have very poor standard of an assumed 'literary competence ${ }^{\prime \prime}$,' the EFL learners' 'literary competence' standard in Duhok Governorate Area's universities in general, the data were statistically analyzed according to the Socialistic Program Statistics Suitcase (SPSS). Table No.3 below presents the findings:

Table 3: Research-sample distribution according to the 'literary competence' standard at the whole study population

\begin{tabular}{|l|l|l|l|}
\hline \multirow{2}{*}{ Indicator } & \multicolumn{3}{|c|}{ Literary competence standard degree } \\
\cline { 2 - 4 } & $\begin{array}{l}\text { Weak } \\
\text { Mark:40 and less }\end{array}$ & $\begin{array}{l}\text { Fair } \\
\text { Mark: 41-58 }\end{array}$ & $\begin{array}{l}\text { High } \\
\text { Mark: 59 and up }\end{array}$ \\
\hline No. & 13 & 71 & 12 \\
\hline Percentage & $13.5 \%$ & $74 \%$ & $12.5 \%$ \\
\hline
\end{tabular}

Findings in Table No.1 indicates that the learners' 'literary competence' standard ranges, in marks, between $24 \%$ and $68 \%$, with statistic mean of (49.56) and standard deviation of (8.58). Depending on the indicator of (meandeviation and mean+deviation), the researcher could classify the research-sample members into 3 groups, according to their degree of 'literary competence' standard:

- Weak (13 out of 96 participants): This group got scores of $(40 \%$ and less), in a percentage of $(13.0 \%)$.

- Fair (71 out of 96 participants): This group got scores of $(41-58 \%)$, in percentage of $(74 \%)$

- High (12 out of 96 participants): This group got scores of (59\% and above), in a percentage of $(12.5 \%)$.
Taking the scores of the 3 groups in account, although they moderately range between $40 \%$ and $59 \%$, the research-sample's community in general could still be found as poorly standardized with regard to 'literary competence'.

Hence, the first hypothesis was proved and accepted.

Secondly: For hypotheses 2 and 4 which successively state that 'No significant differences can be found is the 'literary competence' standard between the EFL learners at 3 universities in Duhok Governorate area" and

"The EFL learners at a tertiary level can develop and improve their 'literary competence' throughout the 4year-college-study"

Table 4: Differences in 'literary competence' standard by university

\begin{tabular}{|l|l|l|l|l|l|}
\hline $\begin{array}{l}\text { Variance } \\
\text { source }\end{array}$ & $\begin{array}{l}\text { Total of } \\
\text { squares }\end{array}$ & $\begin{array}{l}\text { Freedom } \\
\text { degree }\end{array}$ & $\begin{array}{l}\text { Mean of } \\
\text { squares }\end{array}$ & F value & Significant degree \\
\cline { 1 - 4 } $\begin{array}{l}\text { Among the } \\
\text { groups }\end{array}$ & 220.37 & 2 & 110.18 & \multirow{2}{*}{1.541} & No Significance \\
\cline { 1 - 5 } $\begin{array}{l}\text { Inside the } \\
\text { groups }\end{array}$ & 6767.25 & 93 & 72.76 & & \\
\cline { 1 - 5 } Total & 6978.62 & 95 & & \\
\hline
\end{tabular}

Using the ONEWAY ANAOVA as a statistic means, Table No.4, the 'literary competence' standard, by university (hyp.1), signifies that there were no significant differences in the 'literary competence' standard among the EFL learners at NzU, UoD, and UoZ.

Meanwhile, no significant degree of development was detected in the 'literary competence' standard inside each group (hyp.4)
Hence, up to the findings of Table No.4 hyp. 2 is proved and accepted, while for hyp.4 it is nullified and rejected.

Thirdly: For hypothesis 3 which states that "No significant differences can be found in the 'literary competence' standard between the EFL learners at 4 colleges of 3 universities in Duhok Governorate area" See Table No. 5 below: 
Table 5: The differences in 'literary competence' standard by college

\begin{tabular}{|l|l|l|l|l|l|}
\hline $\begin{array}{l}\text { Variance } \\
\text { source }\end{array}$ & $\begin{array}{l}\text { Total of } \\
\text { squares }\end{array}$ & $\begin{array}{l}\text { Freedom } \\
\text { degree }\end{array}$ & $\begin{array}{l}\text { Mean of } \\
\text { squares }\end{array}$ & F value & Significant degree \\
\cline { 1 - 4 } $\begin{array}{l}\text { Among the } \\
\text { groups }\end{array}$ & 30.79 & 2 & 15.39 & \multirow{2}{*}{0.206} & No Significance \\
\cline { 1 - 5 } $\begin{array}{l}\text { Inside the } \\
\text { groups }\end{array}$ & 6956.83 & 93 & 74.80 & \\
\hline Total & 8987.62 & 95 & & \\
\hline
\end{tabular}

Once again the ONEWAY ANOVA method as a 'literary competence' inside the groups due to 4-collegestatistical means was used, no significant differences were detected among the EFL learners' 'literary competence', whether among colleges group in different universities (NoZ, UoD, UoZ) or between colleges group of the same university (UoD). Meanwhile, the findings once again showed that no development happened in the

stages.

Hence, hyp. 3 was validated and accepted, while hyp. 4 was once again nullified and rejected.

Fourthly: For Hypothesis 4 which denotes that "The EFL learners at a tertiary level can develop and improve their 'literary competence' throughout the 4year-college-study", See the table below.

Table 6: Development in 'literary competence' standard by study-stage

\begin{tabular}{|l|l|l|l|l|l|}
\hline $\begin{array}{l}\text { Variance } \\
\text { source }\end{array}$ & $\begin{array}{l}\text { Total of } \\
\text { squares }\end{array}$ & $\begin{array}{l}\text { Freedom } \\
\text { degree }\end{array}$ & $\begin{array}{l}\text { Mean of } \\
\text { squares }\end{array}$ & F value & Significant degree \\
\cline { 1 - 4 } $\begin{array}{l}\text { Among the } \\
\text { groups }\end{array}$ & 73.21 & 3 & 24.40 & \multirow{2}{*}{0,325} & No Significance \\
\cline { 1 - 5 } $\begin{array}{l}\text { Inside the } \\
\text { groups }\end{array}$ & 6914.41 & 92 & 75.15 & \\
\hline Total & 8987.62 & 95 & & \\
\hline
\end{tabular}

Again the ONEWAY ANOVA method as a statistical means was used, there is an absence of significant difference in 'literary competence' standard during the course 4-year-study.

Hence, hyp 4 was nullified and rejected in terms of the aims of this study.

Fifthly: For hypothesis 5 which states that "EFL male-learners can develop better standard of 'literary competence' than that of EFL female-learners.", See the table

below:

Table 7: The significant differences in the 'literary competence' standard according to gender

\begin{tabular}{|l|l|l|l|l|l|l|}
\hline Variable & Gender & No. & $\begin{array}{l}\text { Mathematical } \\
\text { mean }\end{array}$ & $\begin{array}{l}\text { Standard } \\
\text { deviation }\end{array}$ & $\begin{array}{l}\text { T- } \\
\text { value }\end{array}$ & $\begin{array}{l}\text { Significance } \\
\text { degree }\end{array}$ \\
\hline $\begin{array}{l}\text { Literary } \\
\text { competence }\end{array}$ & Male & 48 & 48.31 & 9.57 & \multirow{1}{*}{1.436} & $\begin{array}{l}\text { No } \\
\text { significance }\end{array}$ \\
\cline { 2 - 5 }
\end{tabular}

T-test for 2 independent samples method was used (Table No.7) to analyze the data. The statistical findings detect that T-value is (1.437) with significance degree of (0.05), and with Freedom degree of (94), which eventually means no significant differences in 'literary competence' standard between the two groups of male and female-learners could be found.

Hence, hyp.5 was nullified and rejected.

Sixthly: For hyp.6 which states "that in Duhok Governorate area universities, the tertiary level EFL learners at any state-university can develop better standard of 'literary competence' compared to their peers in the private-sector-universities', because the formers join the university with a total of marks higher than that of the latters, pursuant to the university-applicationregulations in Kurdistan Region-Iraq. Since the data in Tables No. 4 and 5 indicated that no significant differences could be found in 'literary competence' standard among the EFL learners at the 3 universities, this implicitly entail that no significant differences could be found between the state universities and the privatesector universities in this respect.

Hence, hyp. 6 was nullified and rejected as far as the aims of this study are concerned.

\section{0- Conclusions and Recommendations}

\section{0- Conclusions}

In the light of the data analysis in (section 9) above, the following conclusions have been arrived at:

1- Students who joined the tertiary level of education, in particular those who joined a department of English usually come to the college with poor standard of 'literary competence'.

2- Unless they come to college with good precommand of their native language literature, the EFL learner at the tertiary level of education could hardly develop a fair 'literary competence' during the 4-yearcollege-study of English language It could also be implicitly concluded that the development of any 'literary competence' had had better started from the preschool level.

3- $\quad$ Taking into account the fact that the applicants to the state-universities are accepted under the privilege of getting marks in the summative-examination higher than those of their peer-applicants to the private-sectoruniversities, the former could hardly develop a 'literary competence' standard better than that of the applicants to the private-sector universities 
4- Although the impression that circumstances in any patriarch community usually suggests that malelearners have the chance to develop a better 'literary competence' standard compared to female-learners, the research-sample male-learners' group of this study could hardly prove the ability to do so.

\section{0- 2 Recommendations}

In the light of the data analysis and conclusions, the following recommendations can be drawn upon and arrived at:

1- $\quad$ Since the individual's 'literary taste and aesthetic mood' are critically said to be comprehensive, and although studying the novel was taken as a model for the development of an assumed 'literary competence', the findings of this study can be generalized, even if with restrictions, to include poetry and drama study.

2- $\quad$ It is very necessary that during both, the first level and second level of education, greater attention should be paid to not only the 'building of a communicativelyhealthy individual at the prescriptive knowledge', but also 'to the expansion of the scope of the learners' knowledge so as to build up the leaners' aesthetic taste'. In other words, this means arranging literary competitions and founding literary societies within every school for poetry, story, and drama, and consequently 3- $\quad$ A sort of communication should be made between the school-learners at all levels (basic, secondary, tertiary) and the cultural, artistic, and literary societies in the area.

\section{REFERENCES}

Brown, H. D. (1987) Principles of Language Learning and Teaching. USA

Brumfit, C. J. \& Carter R. A. (2000) Literature and Language Teaching. Oxford Oxford University Press Chambers, E. \& Marshal, G. (2006) Teaching E Learning English Literature. London Sage Publication

Duff, Alan and Maley, Alan (2003) Literature. NY-ChinaOxford Oxford University Press
Gill, R. (2006) Mastering English Literature. Great Britain Palgrave Macmillan

Hedge, T. (2003) Teaching and Learning in the Language Classroom. Oxford Oxford University Press

Kumaravadivelu, B (2012) Language Teacher Education for Global Society. New York \& London Routledge

Nizi, N. \& Gautam, R. (2007) How to Study Literature. Tehran Rahnama Press

Short, M. (1969) Exploring the Language of Poems, Plays, and Prose. London \& New York Longman

Swnior, R. M. (2006) The Experience of Language Teaching Cambridge- New York Cambridge University Press

Lazar, G. (2013) Literature and Language Teaching. Cambridge University University Printing House

Watson, G. and Zyngier, S. (2007) Literature and Stylistics for Language Learners. Palgrave Macmillan. Great Britain

Widdowson, H. D. (2003) Defining Issues in English Language Teaching. Oxford Oxford University Press

Appendixes

Appendix I

Names of the jury who examined the questionnaire statements' adequacy:

1- Dr. Hussein Ali Gargari (Prof.)/ College of Languages/ Nawroz University

2- Dr. Chachaan Jum'ah Mohammed (Assist Prof.)/Department of Psychological \& Educational Sciences /Faculty of Basic education/University of Duhok

3- Dr. Sami Abdul-Aziz Al-Ma'mouri (Prof.)/Department of English/College of Basic Education/ University of Diyala.

Appendix II

Note: This questionnaire is exclusively limited to the students who came to college from Kurdish secondary schools, i.e., the English native-speakers or English semi-native speakers, if any, are excluded.

\begin{tabular}{|l|l|}
\hline University: & College: \\
\hline Department: & Stage: \\
\hline Age: & Gender: \\
\hline
\end{tabular}

Dear Student'
The researcher is carrying out a research "Investigating the Literary-competence-
development of the Learners of English as a Foreign Language: The Novel as a Model."
I have the pleasure to benefit from your frank and clear answers to the following
questionnaire items.
Thank you for being helpful.
Researcher
Ahmed Kh. Sha'lan
Nawroz University




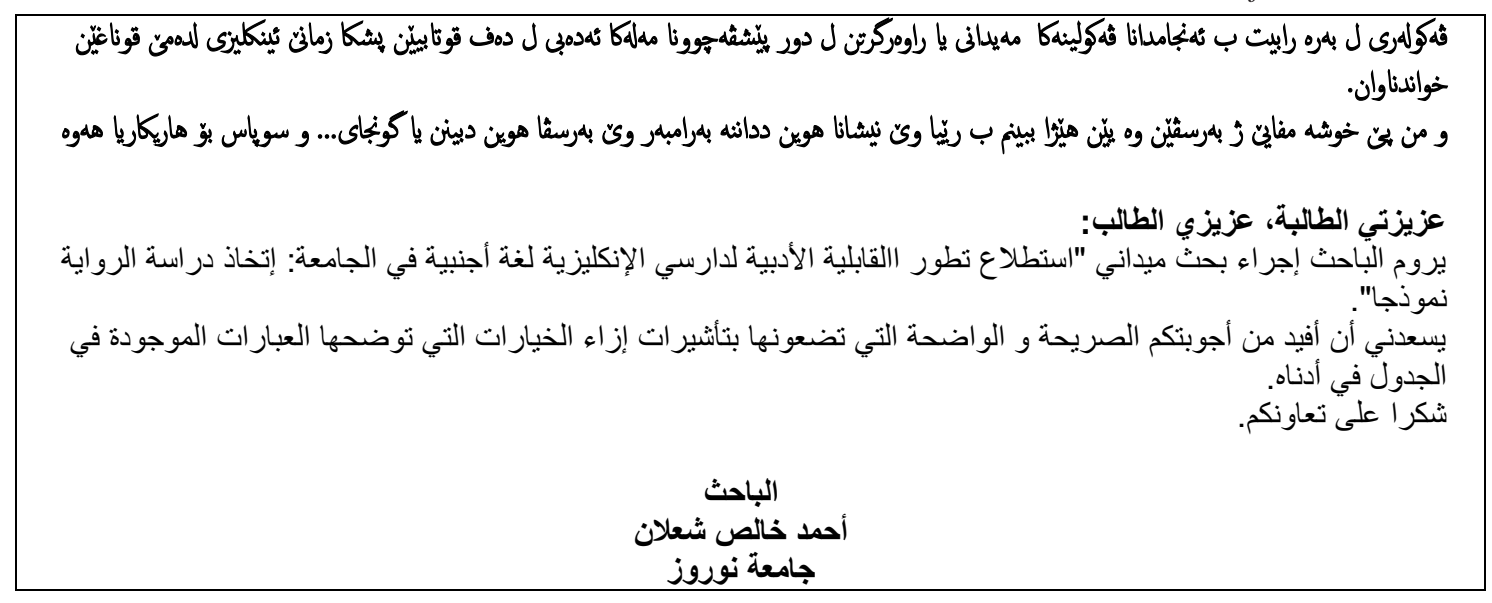

\begin{tabular}{|c|c|c|c|c|c|c|}
\hline No. & Items & Always & Often & $\begin{array}{c}\text { Some- } \\
\text { times }\end{array}$ & Rarely & Never \\
\hline 1 & 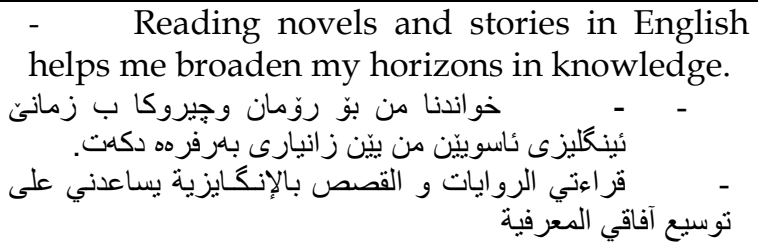 & & & & & \\
\hline 2 & 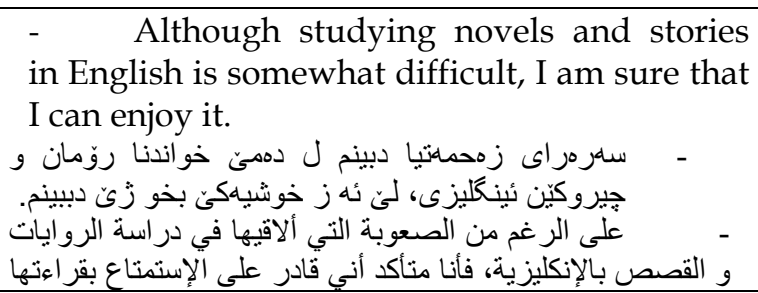 & & & & & \\
\hline 3 & 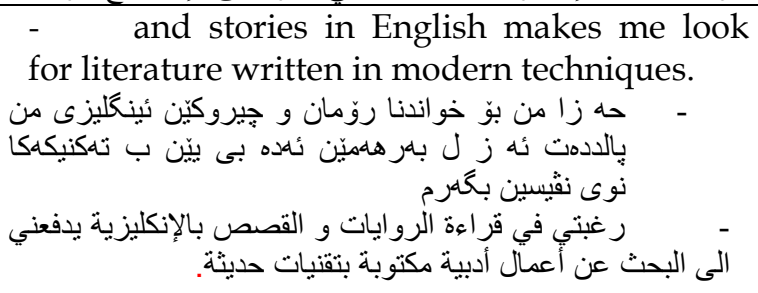 & & & & & \\
\hline 4 & 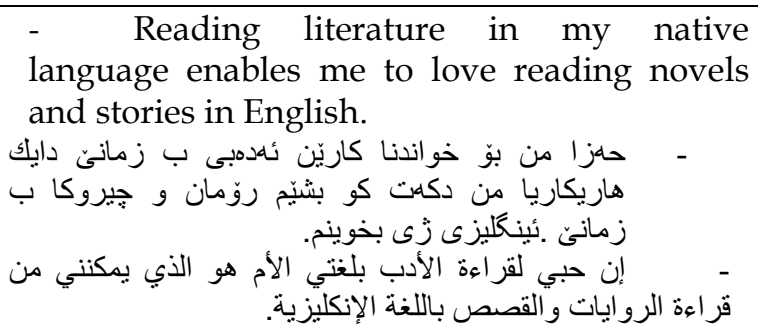 & & & & & \\
\hline 5 & 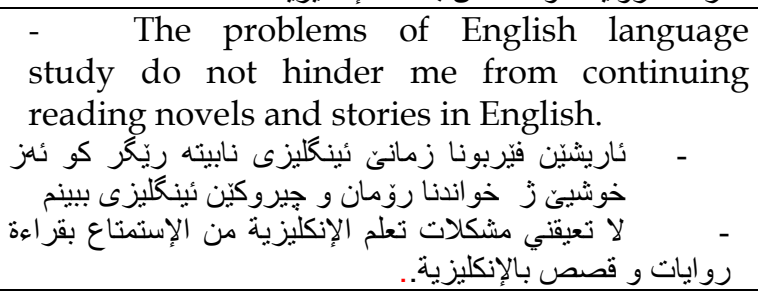 & & & & & \\
\hline 6 & 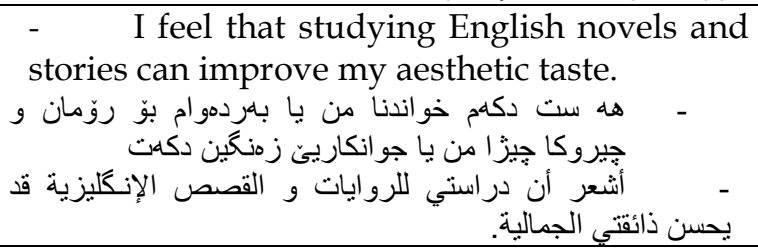 & & & & & \\
\hline
\end{tabular}




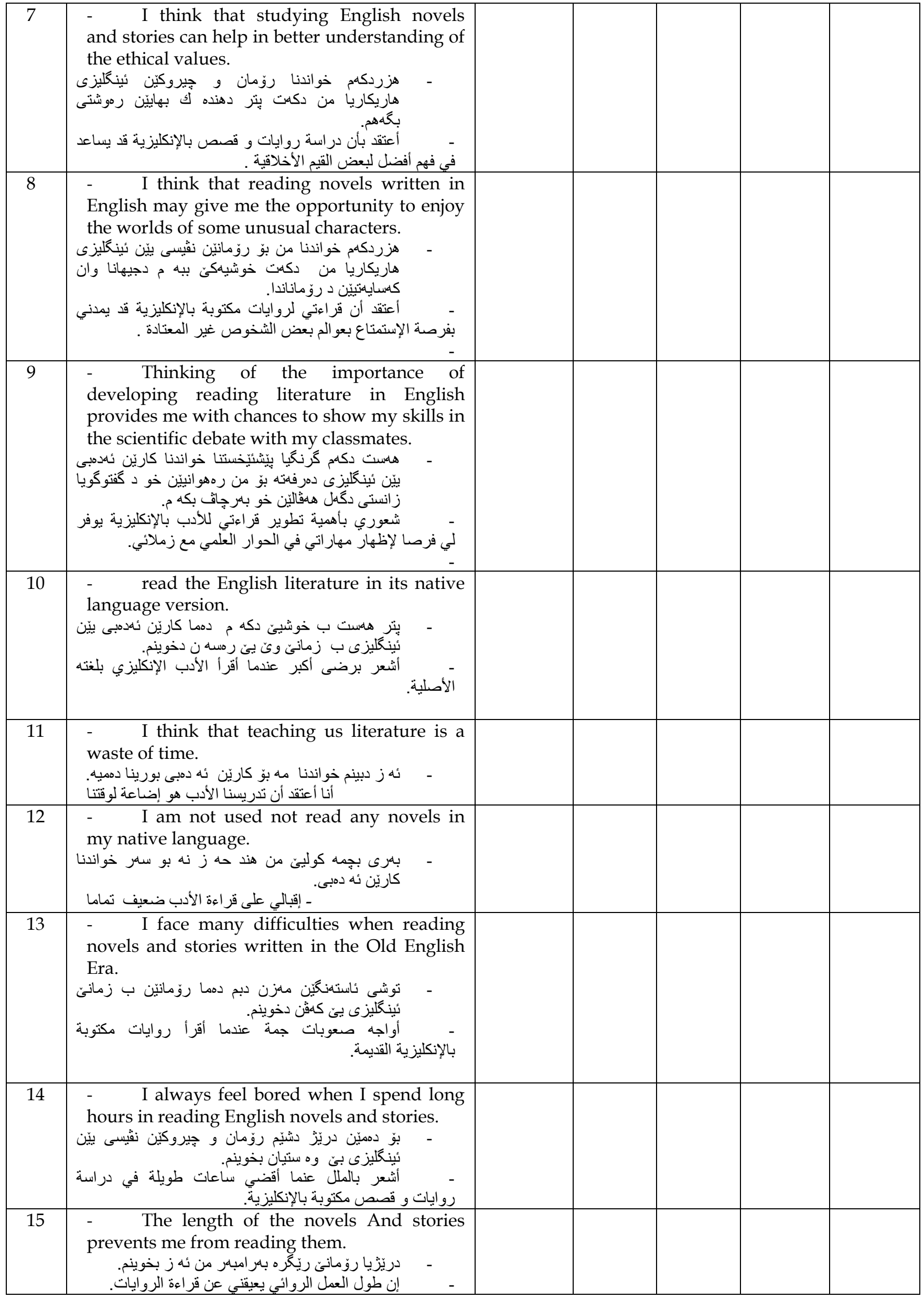




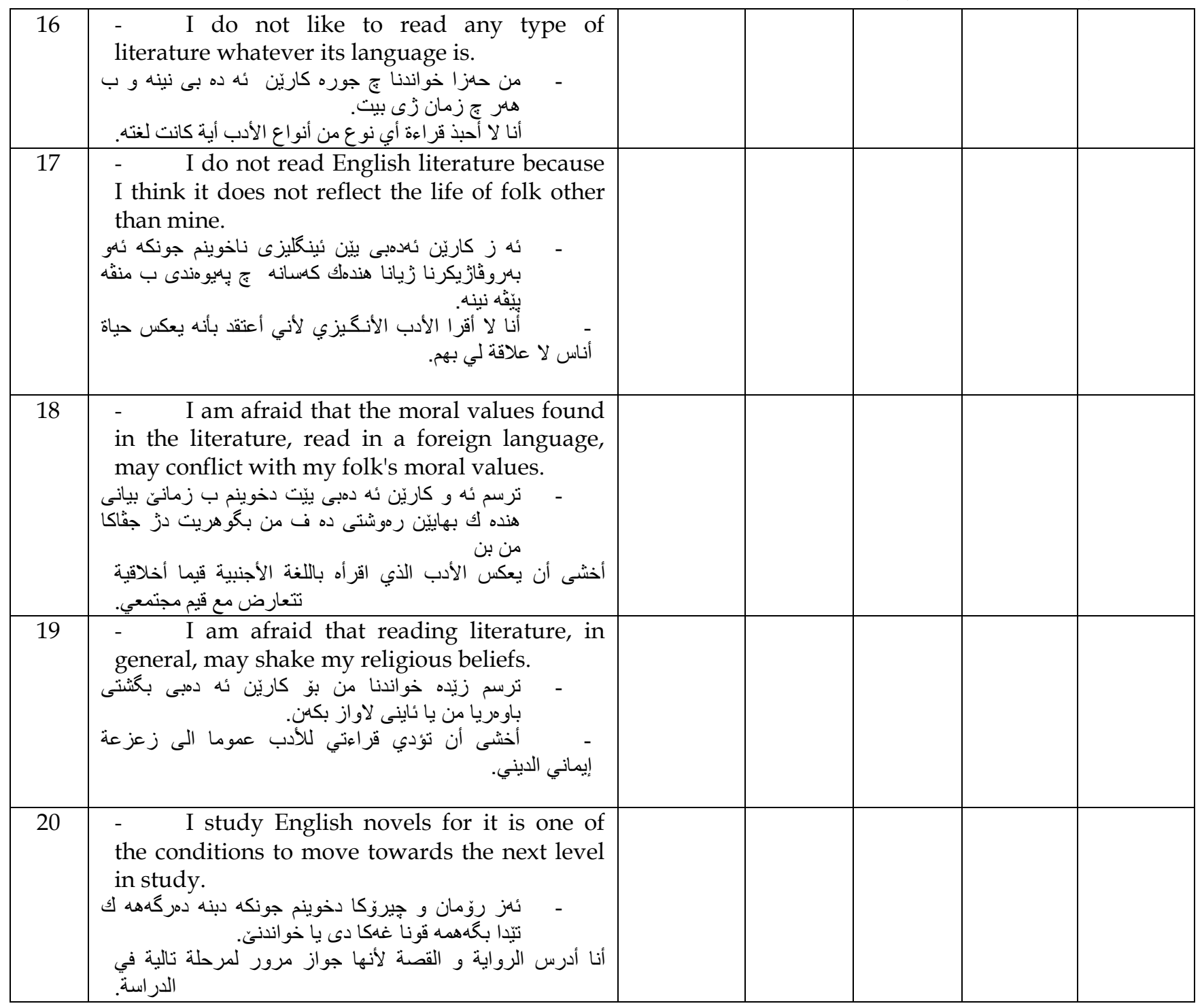

